\title{
Horticultores bolivianos en el interior de la Argentina. Procesos de inmigración, trabajo y asentamiento conflictivo
}

\author{
Roberto Benencia*
}

\begin{abstract}
Resumen
Los inmigrantes bolivianos que se radicaron en áreas rurales del interior de la Argentina, y se dedicaron a la producción hortícola en fresco, si bien fueron minoritarios respecto de los que accedieron al cinturón hortícola de Buenos Aires, transitaron trayectorias similares a las de éstos, pero en algunos aspectos tuvieron que construir otras particulares, relacionadas con las características intrínsecas de las culturas locales.
\end{abstract}

La actividad hortícola en el cinturón verde de la ciudad de Río Cuarto - provincia de Córdobaha experimentado importantes transformaciones en los últimos veinticinco años, impulsada por la llegada de los primeros migrantes de nacionalidad boliviana al sector, a inicios de la década de los '90. De igual modo a como ocurrió en otros cinturones hortícolas del país, el horticultor boliviano introdujo un modelo productivo basado en la utilización de semillas de elevado potencial genético, expansión de la producción en invernadero, modificaciones en la organización del trabajo y cambios en la tecnología de sistemas de riego, habilidades que había aprendido en otras áreas hortícolas de la Argentina; esto derivó en la consolidación de un importante núcleo de producción diversificada de hortalizas, tanto en cantidad como en calidad, para la ciudad de Río Cuarto y una amplia zona de influencia.

\section{Palabras Clave}

Agricultura; Migraciones; Producción hortícola; Bolivia; Argentina.

\section{TITLE}

Bolivian horticulturists in Argentina: Immigration processes, work and conflictive settlement

\section{Abstract}

The bolivian immigrants that settled in rural areas of Argentina and work in horticultural production have made similar trajectories to those who went to work in the horticultural central belt of Buenos Aires. However, they did develop other particularities in some respects, related with the intrinsic characteristics of the local cultures.

The horticultural activity in the green belt of the city of Rio Cuarto (province of Cordoba) has experienced significant transformations in the last 25 years, boosted by the arrival of the first bolivian migrants to the sector during the first decade of the $90 \mathrm{~s}$. In the same way as in other horticultural belts in the country, the bolivian horticulturist introduced a model of production based on certain elements: the use of genetically modified seeds, the expansion of greenhouse production, modifications in the organization of work, and changes in risk systems technology. These were skills that had been learnt in other horticultural areas in Argentina. This led to the consolidation of the city of Rio Cuarto and its wider sphere of influence as an important nucleus for the diverse production of vegetables, both in quantity and quality.

\section{KEYWORDS}

Farming; Migrations; Horticultural production; Bolivia; Argentina.

\section{* Roberto BE-} NENCIA, Investigador del CONICET; profesor de la Facultad de Agronomía de la Universidad de Buenos Aires y profesor de la Universidad Nacional Arturo Jauretche.

DOI: $10.15366 /$ relacionesinternacio nales2017.36.010

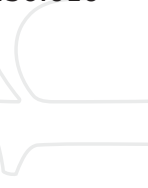




\section{ntroducción}

Los inmigrantes bolivianos que se radicaron en áreas rurales del interior de la Argentina, si bien fueron minoritarios respecto de los que accedieron al cinturón hortícola de Buenos Aires, transitaron trayectorias similares a las de aquellos, en algunos aspectos, y tuvieron que construir otras particulares, relacionadas con las características intrínsecas de las culturas locales.

La actividad hortícola en el cinturón verde de la ciudad de Río Cuarto - provincia de Córdoba - ha experimentado importantes transformaciones en los últimos años, impulsadas por la llegada de los primeros migrantes de nacionalidad boliviana al sector a principios de la década de los 90. De igual modo, como ocurrió en otros cinturones hortícolas del país, el productor boliviano introdujo un modelo productivo basado en la utilización de semillas de elevado potencial genético, expansión de la producción en invernadero, modificaciones en la organización del trabajo y cambios en la tecnología de sistemas de riego, que había aprendido en otras áreas hortícolas de la Argentina; esto derivó en la consolidación de un importante núcleo de producción diversificada de hortalizas, tanto en cantidad como en calidad, para la ciudad de Río Cuarto y una amplia zona de influencia.

A partir de ello, la ciudad comenzó a atraer a otros trabajadores bolivianos, en particular, mano de obra para la producción de ladrillos, que pudieron satisfacer la demanda emergente de materiales básicos para la construcción, en virtud del crecimiento inmobiliario de la ciudad, como consecuencia de las inversiones derivadas de la soja y el maní, dos cultivos extensivos muy importantes en el agro riocuartense.

En este artículo vamos a hacer referencia, en particular, a la inserción de los migrantes bolivianos en la producción hortícola del departamento y, paralelamente, al éxito consecuente obtenido por dichos actores sociales a partir de su involucramiento en esta actividad; así como también, a la reacción violenta que produjo dicho éxito entre la población local de bajos recursos económicos.

Con este objetivo, se analizarán las características de la inserción exitosa de los inmigrantes bolivianos en el área de referencia, básicamente, a partir de una encuesta a los integrantes de dicha población, y entrevistas en profundidad realizadas a la totalidad de ellos -15-, en algunos casos más de una vez, a lo largo de los tres años que duró la investigación. Así como también se apeló a técnicas de observación con participación, a través de las cuales se pudo apreciar su evolución laboral y económica desde su llegada a Río Cuarto hasta la actualidad. Paralelamente a la captación de sus capacidades para lograr una evolución exitosa en la horticultura, se buscó desentrañar, así mismo, los procesos negativos de una integración conflictiva en relación con los productores y comercializadores locales, así como con trabajadores y vecinos del área; para lo cual se recurrió también a información provista por los diarios de la zona, tanto los producidos en papel como en internet.

\section{La horticultura riocuartense en el contexto histórico}

Según estudios previos ${ }^{1}$, la producción hortícola en la ciudad de Río Cuarto se origina hacia

1 CORRAL, Mario et al, Diagnóstico y evolución del área frutihortícola de Río Cuarto,Comisión de Desarrollo 
comienzos del siglo XX, principalmente con la llegada de inmigrantes italianos, españoles $y$, en menor medida, franceses y árabes. Durante las primeras décadas del siglo pasado se desarrollaban cultivos como frutilla, batata y espárrago con excelentes rendimientos. A partir de 1930 comienza a expandirse el cultivo de papa, y así surgen establecimientos hortícolas empresariales con producción especializada que llegan a ocupar una superficie de 11.000 ha durante la década del 60.

A partir de 1967, con la creación del Mercado de Abasto de Río Cuarto (MARC), los productores hortícolas incorporan en sus establecimientos una amplia variedad de cultivos, diversificando la producción en la zona. En 1975 los cultivos con mayor importancia económica eran lechuga, batata, papa, repollo y zapallito de tronco, manifestándose una importante reducción de la superficie cultivada con espárrago, al tiempo que comenzaban a disminuir la rentabilidad de la papa y del ajo, principalmente por problemas sanitarios y de mercado.

En el período 1980-1984, el área hortícola de Río Cuarto abarcaba unas 440 ha, con predominio de cultivos como acelga, lechuga, batata, maíz para choclo, zapallito y remolacha. Los últimos estudios, realizados a inicios de la década del 90, marcaron un crecimiento de la superficie hasta alcanzar unas 540 ha con 25 especies hortícolas en cultivo, siendo las de mayor importancia las hortalizas de hoja.

Hasta el inicio de dicha década, los productores hortícolas eran argentinos, criollos o descendientes de italianos, y buena parte de la verdura para la ensalada -básicamente, tomate y pimiento - se importaba de otras regiones de Argentina.

\section{Los inmigrantes bolivianos que llegaron a Río Cuarto}

Alrededor de la década del 90, comenzaron a arribar a Río Cuarto inmigrantes bolivianos que se dedicaron a la producción de hortalizas, dando inicio a la creación de un "nuevo territorio hortícola" en el país, conformado básicamente por productores de dicha nacionalidad.

Estos inmigrantes no arribaban directamente desde Bolivia a este departamento del sur de Córdoba, sino que desde hace varias décadas venían migrando periódicamente hacia Argentina, para regresar hacia su propio país y reanudar el ciclo nuevamente; en un inicio, para trabajar como cosecheros del algodón, del tabaco, de la caña de azúcar en territorios contiguos a su país, o como peones en la construcción, los hombres, y en el servicio doméstico, las mujeres, en áreas urbanas; hasta que, en determinado momento, descubren la demanda de mano de obra en la horticultura periurbana de Argentina, y comienzan a dirigirse hacia dichos lugares: Buenos Aires, Mar del Plata, Mendoza, Salta, Tucumán, donde son requeridos inicialmente en carácter de trabajadores o medianeros, y con el tiempo se fueron transformando en productores especializados en esta actividad.

Durante 2003, en una visita realizada a Río Cuarto, se pudo captar este fenómeno de bolivianos trabajando en la horticultura, que nos llevó a tratar de comparar con el proceso que había estudiado en el área hortícola bonaerense años atrás; pero aquí, podíamos tratar

Regional, Universidad Nacional de Río Cuarto, Río Cuarto, 1993; AGÜERO, Daniel y GROSSO, Liliana, El sector hortícola del cinturón verde de Río Cuarto, Facultad de Agronomía y Veterinaria, Universidad Nacional de Río Cuarto, 2004. 
de observarlo a partir de la llegada del pionero².

\section{Situación actual en Río Cuarto: el rol del inmigrante boliviano en la producción de hortalizas}

Si bien en el punto anterior, mencionamos que pudimos captar el inicio de un proceso en el área hortícola de Río Cuarto; aproximadamente 14 años más tarde puede apreciarse que la actividad hortícola del cinturón verde de Río Cuarto está conformada por 33 establecimientos dedicados a la producción exclusiva de hortalizas, correspondiendo 18 de ellos a productores de origen local $-55 \%-$, y 15 a productores bolivianos $-45 \%-$. La superficie total que ocupan hoy las quintas hortícolas es de 511 ha, con una superficie efectiva destinada a la producción de hortalizas, tanto a campo como en invernadero, de 378 ha $^{3}$.

Los establecimientos se distribuyen en seis áreas principales ubicadas en la zona nor-noroeste y nordeste de la ciudad de Río Cuarto, donde se identifican los sectores de Tres Acequias -76 ha-, Barrio Las Quintas -83 ha-, Colonia San José $-6,3$ ha-, Ex ruta Nacional No $36-88$ ha-, Seminario -179 ha- y Palestro -78 ha-. Antiguamente los sectores más relevantes en superficie de producción los constituían la zona de Tres Acequias y Barrio Las Quintas, sin embargo, en la actualidad se ha producido un desplazamiento importante de productores hacia las zonas del Seminario y Palestro -Véase mapa-.

\section{Mapa del territorio hortícola de Río Cuarto, donde se han localizado los establecimientos hortícolas en la actualidad}

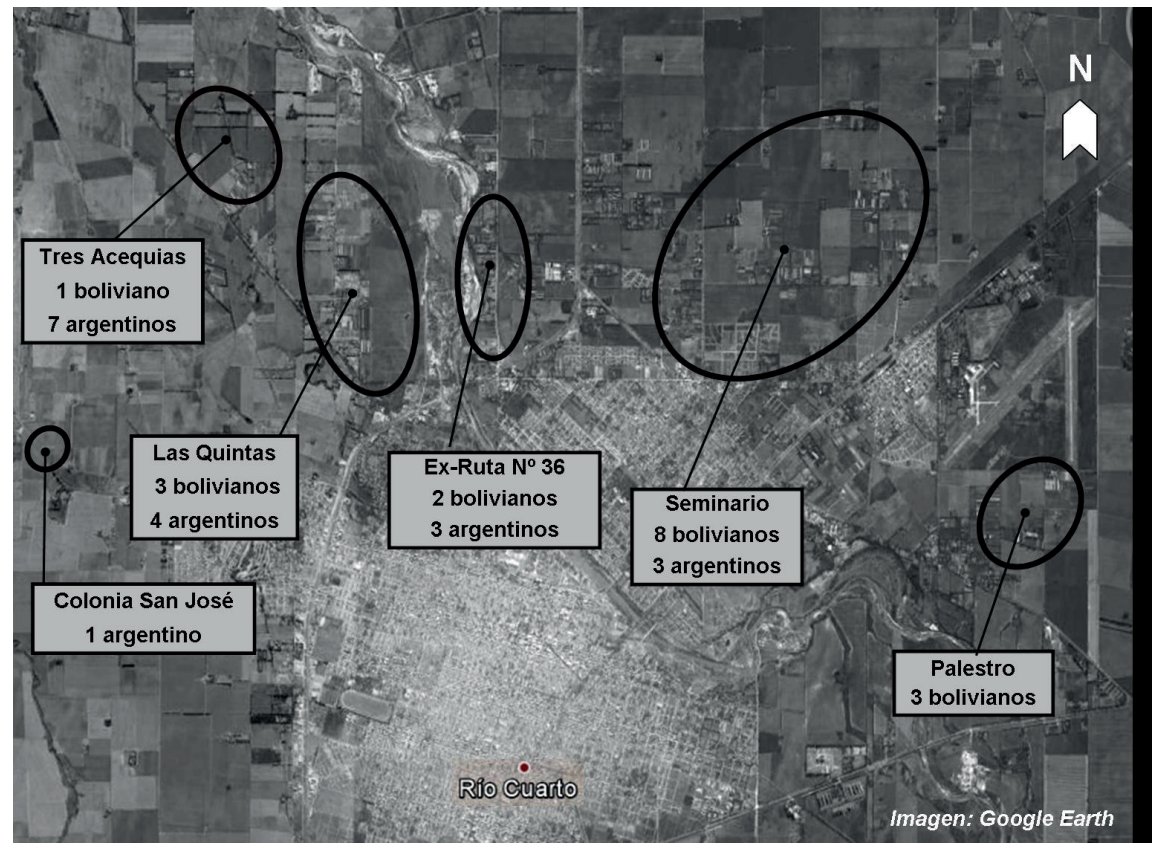

Fuente: la imagen corresponde a Google Earth, y las localizaciones de los establecimientos hortícolas en relación con las áreas rurales específicas del Departamento de Río Cuarto fueron realizadas por el equipo de investigación.

BENENCIA, Roberto y GEYMONAT, Marcela, "Migración transnacional y redes sociales en la creación de territorios productivos en la Argentina. Río Cuarto, Córdoba" en Cuadernos de Desarrollo Rural, n 55, 2005, pp. 9-28.

3 Los datos a que se hace referencia provienen de una encuesta realizada a todos los horticultores del área de referencia por los integrantes de la Cátedra de Horticultura de la Universidad de Río Cuarto, Diego Ramos y Fabricio Salusso, bajo la supervisión de Roberto Benencia, durante el período 2014-2015. 
Las causas de este fenómeno ocurrieron, por un lado, como consecuencia de cambios en las actividades impulsadas principalmente por las generaciones actuales de los productores nacionales, que han decidido incursionar en otros rubros de producción, como cultivos de soja, maíz y alfalfa para corte, así como también orientar su vida laboral hacia otros sectores económicos ajenos a la producción, y por otro lado, a la imposibilidad de utilizar agua para riego proveniente de las acequias de la zona debido a una importante disminución de la altura del río Cuarto en ese sector.

Así, los migrantes bolivianos en la búsqueda de nuevas tierras para asentarse encuentran los sectores del Seminario y Palestro como potenciales sitios de producción, lo que lleva a conformar un importante núcleo productivo representado en la actualidad por un $61 \%$ de productores de este origen ${ }^{4}$.

El tamaño de las explotaciones es de pequeño a mediano, con superficies que varían de 2 ha hasta un máximo de 26 ha, siendo el promedio de 9,6 ha. El 59\% de los productores tiene una superficie inferior al promedio, y el $41 \%$ supera ese valor. Al analizar el régimen de tenencia de la tierra, el $58,5 \%$ de la superficie es propia y el $41,5 \%$ arrendada, con un importante predominio de productores bolivianos bajo este último sistema de tenencia 5 .

En este sentido, los productores bolivianos luego de trabajar cierto tiempo en relación de mediería ${ }^{6}$, o a porcentaje con su empleador, acceden a la tierra como arrendatarios, y finalmente, algunos han logrado la propiedad de éstas, aumentando el número de establecimientos hortícolas bajo su conducción.

En la actualidad, los productores bolivianos poseen unas 98 ha en propiedad, y arriendan un total de 178 ha; a diferencia de los productores locales, que son propietarios de 201 ha y sólo arriendan 34 ha7. Estos resultados surgen como consecuencia de la racionalidad empresarial del productor; quienes son arrendatarios, como muchos de los productores bolivianos, no cultivan especies hortícolas de ciclo muy largo, ya que mensualmente deben cubrir los costos del arrendamiento y, por ende, prefieren cultivar especies más precoces, que brindan un retorno más rápido del capital invertido.

\footnotetext{
${ }^{4}$ La información proviene de la encuesta de referencia mencionada con anterioridad.

5 Ibídem.

6 La "mediería" es una relación contractual -especie de aparcería-, en la cual se asocia el trabajador con el poseedor de la tierra y el capital en la realización de determinados cultivos, desligándose, de este modo, aquél de 1a contratación de otro tipo de trabajadores - salvo, lógicamente, la participación de la mano de obra de su propia familia-, ya que la misma es aportada íntegramente por el "mediero", quien puede trabajar con su familia y/o contratar personal para determinadas labores - sea que se requiera personal de baja calificación, como los peones transitorios, o con cierta especialización, como los embaladores de tomates-. La retribución por las tareas entre patrón y mediero se pacta sobre un porcentaje de lo obtenido por la venta de lo cosechado en la parcela de referencia. Este puede alcanzar el $40 \%$, cuando el mediero se hace cargo de la mitad de los insumos, o reducirse al $25 \%$, cuando no aporta más que el trabajo. La relación entre patrón y mediero generalmente es de palabra, salvo en el caso de la zona de La Plata, donde la estructura hortícola aparece más consolidada, sus quintas -establecimientos hortícolas - datan de principios de siglo; allí existen contratos legalizados. El productor aporta la tierra y la mitad de los insumos - semillas, plaguicidas, etcétera-, en tanto que el mediero contribuye con la otra mitad y la fuerza de trabajo; por ello se acuerda que habrá de recibir un $40 \%$ de lo que se perciba por la venta de lo producido en "su parcela", que el mismo patrón se encarga de comercializar. En general estos porcentajes tratan de ser regulados - acordados- mutuamente por los propios patrones quinteros del área, pues al no haber nada firmado, los medieros podían irse a otras quintas si les ofrecieran un porcentaje mayor.

${ }^{7}$ Esta información proviene de la encuesta de referencia.
} 
Un ejemplo muy claro de esta estrategia es el cultivo de zanahoria, cuyo ciclo se extiende de 5 a 6 meses, por lo cual sólo es llevado a cabo por productores locales propietarios de sus tierras.

La mano de obra presente en el sector involucra a un total de 185 trabajadores, siendo el $83 \%$ de origen boliviano y sólo el $17 \%$, de origen argentino; estos valores incluyen a los propios productores, ya que debido a las características de intensividad del cultivo, también deben trabajar en su propio establecimiento. Los productores bolivianos emplean un $99 \%$ de mano de obra boliviana -113 trabajadores- y sólo un $1 \%$ de mano de obra local -1 trabajador-. En cambio, en los establecimientos de productores locales el 58\% de la mano de obra es de origen boliviano -41 trabajadores - y el $42 \%$ de origen local -30 trabajadores-. Esto demuestra la importancia de la mano de obra boliviana en el total de la producción de hortalizas en el cinturón hortícola riocuartense ${ }^{8}$.

La creciente participación de productores de nacionalidad boliviana en el sector es similar al proceso que se ha dado en otras áreas de producción hortícola en fresco en el país; por ejemplo, en la zona oeste del cinturón verde de la ciudad de Buenos Aires, el modelo productivo desarrollado a partir de la expansión de productores bolivianos implicó una mayor oferta de hortalizas, ya sea por incremento de la producción -básicamente, adopción del invernadero- como por incorporación de nuevas zonas productivas; además, la adopción de la mediería como razón social del trabajo y la difusión del cultivo en invernadero fueron componentes centrales de la reconfiguración de esos sectores de la producción ${ }^{9}$.

Otro caso similar es el desarrollo ocurrido en el partido de Florencio Varela -Buenos Aires-, donde cerca de la mitad de los establecimientos hortícolas se encuentran a cargo de productores de nacionalidad boliviana. Se trata de migrantes con más de 10 años de residencia en el país. La superficie promedio de los establecimientos es de 3 ha, y un $70 \%$ de las quintas a cargo de bolivianos llevan a cabo cultivos bajo invernadero ${ }^{10}$.

En Río Cuarto, los establecimientos hortícolas son diversificados con más de 30 especies de hortalizas producidas a campo. Entre los principales se destacan las hortalizas de hoja, como lechuga crespa, lechuga arrepollada y lechuga mantecosa, acelga, repollo, espinaca, achicoria y perejil. La superficie a campo destinada a cada cultivo hortícola no ha variado significativamente en los últimos años, notándose un incremento en nuevos cultivos, como rúcula, achicoria y espinaca, así como un desplazamiento de la producción de tomate y de pimiento a campo hacia el uso de invernaderos.

En este sentido, la producción bajo invernadero en el área ha sido uno de los cambios tecnológicos más importantes acontecidos en el sector en los últimos años, y que fue llevado adelante por productores bolivianos. El cinturón verde de Río Cuarto cuenta con 178

\footnotetext{
8 Esta información proviene de la encuesta de referencia.

9 BENENCIA, Roberto et al,"Organización socio-productiva de la horticultura del partido de Florencio Varela" en Boletín Hortícola, INTA Buenos Aires, 2013.

${ }^{10}$ BENENCIA, Roberto et al,"Organización socio-productiva de...", op.cit.
} 
invernaderos que cubren una superficie aproximada de 19.8 hectáreas ${ }^{11}$.

\section{La importancia de las nuevas tecnologías en la producción hortícola en fresco}

En lo que respecta al uso de las nuevas tecnologías, puede apreciarse que el $80 \%$ de los productores bolivianos produce bajo "invernadero" -15.70 ha-, a diferencia de los productores nacionales, entre los que sólo el 39\% tiene invernaderos -4.16 ha- ${ }^{12}$ existiendo, inclusive, reticencia por parte de estos últimos a la incorporación de esta forma de producción. Un factor interesante a considerar, cuando se realiza un análisis de la mano de obra utilizada en la producción bajo invernadero, es que un $95 \%$ es de origen boliviano y sólo un $5 \%$ de origen local ${ }^{13}$.

Los principales rubros de producción en invernadero incluyen unas 12 especies hortícolas, donde se destacan tomate y pimiento en la época primavera-estival y posteriormente hortalizas de hoja durante el otoño e invierno, como lechuga crespa, lechuga mantecosa, espinaca, apio, rúcula y achicoria.

Esta situación replica lo que se aprecia en otras zonas de horticultura en fresco en el país: a partir de la segunda mitad de la década del 90 se generalizó en el partido de La Plata - Buenos Aires - la presencia del invernadero en la producción de hortalizas, que asociado a la mediería como forma social del trabajo se constituyó en la modalidad productiva predominante en las quintas más dinámicas del cinturón hortícola de la ciudad de Buenos Aires ${ }^{14}$.

Los modelos de invernadero que predominan en el cinturón de Río Cuarto son del tipo capilla modificado - con ventilación cenital-, en menor medida, el tipo capilla, y, en la actualidad, ha comenzado a difundirse el modelo tipo doble capilla, debido a que el único constructor idóneo que existe en la zona es de origen boliviano y desarrolla este tipo de modelo. Todos los invernaderos poseen estructura de postes de madera de eucaliptus y palmera, y los materiales de cubierta son polietilenos térmicos.

Otro cambio importante introducido en el sector por productores bolivianos ha sido el sistema de "riego por aspersión". Anteriormente los productores locales regaban por inundación, empleando agua del río Cuarto; la incorporación de sistemas de aspersión derivó no sólo en cambios en la forma de producción y organización espacial de los cultivos, sino que, además, sumado a la expansión del invernadero con sistemas de riego por goteo, llevó a lograr una mayor eficiencia en el uso del agua para riego.

El cinturón hortícola de Río Cuarto abastece con hortalizas de hoja durante todo el año a la ciudad y a una gran zona de influencia que abarca desde el sur y este de Córdoba, parte de San Luis y norte de La Pampa, provincias que limitan con Córdoba. La oferta de hortalizas de fruto - como tomate, pimiento, berenjena y cucurbitáceas- sólo cubre la demanda durante

\footnotetext{
${ }^{11}$ Esta información proviene de la encuesta de referencia.

12 Ibídem.

${ }^{13}$ Ibíd.

${ }^{14}$ BENENCIA, Roberto et al,"Organización socio-productiva de...", op.cit.
} 
la época de producción de estos cultivos, que comprende desde fines de primavera hasta principios del otoño; durante el resto del año, dichos productos se importan desde zonas de primicia.

La comercialización se realiza a través del Mercado de Abasto de Río Cuarto (MARC), una sociedad mixta con un $51 \%$ de las acciones pertenecientes a la municipalidad de Río Cuarto - capital público- y el $49 \%$ restante distribuido entre puesteros y playeros -capital privado-. Los puestos corresponden a comerciantes locatarios que introducen mercadería de otras zonas, principalmente artículos que no se producen localmente, como papa, ajo, cebolla y frutas, y las playas son para productores locales, operadores permanentes que venden su propia producción y la de otros productores. En total existen 32 playeros que operan en el mercado, siendo el $53 \%$ productores nacionales y un $47 \%$ bolivianos.

La totalidad de los productores bolivianos posee una playa en alquiler en el MARC, siendo ésta la única vía de comercialización, en contraste con productores de mercados como el de Florencio Varela, en el Gran Buenos Aires, por ejemplo, donde si bien el $40 \%$ de los productores bolivianos poseen puestos en un mercado concentrador, un porcentaje similar entrega la producción a consignatarios, y alrededor de un $27 \%$ vende su producción en la tranquera del mismo establecimiento. Esta última modalidad de comercialización expone al productor a una alta vulnerabilidad al momento de negociar la producción ${ }^{15}$.

\section{5. ¿Podemos hablar de economías étnicamente controladas?}

¿Cómo se catalogan conceptualmente estos procesos migratorio-laborales donde se produce una concentración de inmigrantes de una misma nacionalidad en algún aspecto de la economía del país receptor? ¿Y en la que tanto los patrones como los empleados pertenecen a la misma nacionalidad migrante?

La literatura especializada en los aspectos de la economía relacionados con la migración que se ha ocupado de este tipo de inserción de los inmigrantes en el país de destino denomina a estos fenómenos socioeconómicos con el concepto de economías o negocios étnicos. ¿Podemos hablar de negocios étnicos en el caso de la horticultura en fresco en la Argentina, y en particular de Río Cuarto?

Según Arjona Garrido y Checa Olmos ${ }^{16}$, la consideración de las actividades empresariales regentadas por extranjeros como economías étnicas está estrechamente relacionada con una serie de variables que subyacen a la situación:

- Concentración espacial y étnica

- Tipo de negocios

- Número de empleados y nacionalidad

- Clientela

- Recursos utilizados; etcétera.

15 BENENCIA, Roberto et al,"Organización socio-productiva de...", op.cit.

${ }^{16}$ ARJONA GARRIDO, Angeles y OLMOS, Juan Carlos, "Emprendedores étnicos en Almería. ¿Una alternativa laboral a la segmentación del mercado de trabajo?" en Sociología del Trabajo, Nueva Epoca, n 54, primavera, Madrid, 2005, pp: 101-126. 
Es decir, variables que presentan connotaciones sociológicas y antropológicas que deben ser abordadas, puesto que derivan en conceptos -economía étnica, economía de enclave, economía de propiedad étnica y economía de control étnico ${ }^{17}$ - con particularidades diferentes.

\section{Economía étnica}

Según los autores mencionados, la economía étnica incluye a cualquier persona inmigrante que sea empleador, autoempleador o que esté empleado en empresas coétnicas.

"El contorno de una economía étnica está definido por raza, etnicidad u origen nacional, caracterizándose por alcanzar ventajas en las relaciones entre propietarios de negocios y entre propietarios y trabajadores del mismo origen nacional"18.

A lo que otros investigadores del campo de los emprendedores étnicos han sumado la función de "escuela de emprendedores"19, ya que facilita la formación para el autoempleo.

\section{Enclave étnico}

El concepto de enclave étnico, a diferencia del de economía étnica, introduce una referencia explícita a la dimensión espacial ${ }^{20}$, pues el espacio no actúa únicamente como un contenedor material de la población, sino también de relaciones sociales. De este modo, los enclaves requieren de una gran densidad de población inmigrante, para asegurarse una extensa clientela a partir de las relaciones sociales y de la solidaridad étnica. A su vez, en el enclave se cuenta con fuerza de trabajo coétnica a disposición del empresario, configurando, al mismo tiempo, un espacio de socialización y de autoayuda.

No obstante, según Portes y Jensen ${ }^{21}$, en la configuración de los enclaves se encuentra gran diversidad de situaciones:

- primero, aquellos que viven y trabajan en el área del enclave;

- segundo, quienes trabajan en esta área, pero viven fuera;

- tercero, quienes viven en el área del enclave, pero trabajan fuera de él;

- cuarto, aquellos miembros del grupo étnico que ni viven ni trabajan en el área del enclave.

El "contexto de recepción", estrechamente relacionado con la segmentación, es otro elemento clave a la hora de entender la incorporación laboral de los inmigrantes. Gran parte de las estrategias que ponen en marcha los inmigrados para su inserción laboral dependen, en muchas ocasiones, de factores contextuales y estructurales $y$, en otras, de factores

${ }^{17}$ ARJONA GARRIDO, Angeles. Inmigración y mercado de trabajo. El caso de la economía étnica en Almería, Universidad de Almería, Almería, 2004.

18 LOGAN, John R., ALBA, Richard y McNULTY, T.L., "Ethnic Economies in Metropolitan Regions. Miami and Beyond" en Social Forces, no 72, 1994.

19 LIGHT, Ivan y KARAGEORGIS, Stavros, "The ethnic economy" en SMELSER, Neil y SWEDEMBERG, Richard (edit.) The handbook of economic sociology, Nueva York, Russell Sage Foundations, 1994, pp: 650-677.

20 PORTES, Alejandro y WILSON, Kenneth. "Immigrants enclave: An analysis of the labor market experiences of Cubans in Miami" en American Journal Sociology, vol. 86, no 2, 1980, pp: 295-319.

${ }^{21}$ PORTES, Alejandro y JENSEN, Leif, "The enclave and the entrants: patterns of ethnic enterprise in Miami before Mariel" en American Sociological Review, vol. 54, no 6, 1989, pp: 929-949. 
individuales -capital humano y social-.

En los trabajos de Portes y sus colaboradores se destaca la idea de que el capital humano del inmigrado está a expensas de los factores contextuales, los cuales están totalmente controlados por determinados agentes sociales y económicos. Entre ellos hay que resaltar: las condiciones de salida del país de origen, la política internacional de flujos, los contextos de recepción, la trayectoria de los primeros llegados o los tipos de comunidades que ya se han creado en destino22. La idea central de este modelo afirma que "...un particular contexto de salida y recepción puede tener un desarrollo social diferente y unas condiciones culturales para los miembros de un origen nacional distinto..."23.

Así, y como se esquematiza en el siguiente cuadro, la inserción laboral de los inmigrados, en función del contexto de acogida, puede ser, en primer lugar, hostil, cuando se produce un acceso al mercado en el segmento secundario y los empresarios étnicos se convierten en "minorías intermediarias"24; en segundo lugar, neutral, los inmigrantes se insertan en ambos segmentos de los mercados, y los autónomos pueden crear empresas dominantes en algunos sectores; en último lugar, favorable, cuando se accede a empresas y los emprendedores pueden formar economías de enclave.

\section{Contextos de recepción e incorporación laboral del inmigrado}

\begin{tabular}{|c|c|c|c|}
\hline & Trabajo manual & $\begin{array}{c}\text { Profesionales } \\
\text { técnicos }\end{array}$ & Empresarios \\
\hline Hostil & $\begin{array}{c}\text { Acceso al mercado } \\
\text { secundario }\end{array}$ & $\begin{array}{l}\text { Proveedores } \\
\text { de servicios } \\
\text { marainales }\end{array}$ & $\begin{array}{c}\text { Minorías } \\
\text { intermediarios }\end{array}$ \\
\hline Neutral & $\begin{array}{c}\text { Participación en el } \\
\text { mercado laboral } \\
\text { mixto }\end{array}$ & $\begin{array}{c}\text { Acceso al } \\
\text { mercado primario }\end{array}$ & $\begin{array}{c}\text { Pequeña } \\
\text { empresa } \\
\text { dominante }\end{array}$ \\
\hline Favorable & $\begin{array}{c}\text { Posibilidades } \\
\text { de acceso a la } \\
\text { pequeña empresa }\end{array}$ & $\begin{array}{c}\text { Posibilidades de } \\
\text { acceso a puestos } \\
\text { de liderazgo } \\
\text { profesional y } \\
\text { social }\end{array}$ & $\begin{array}{c}\text { Economías de } \\
\text { enclave }\end{array}$ \\
\hline
\end{tabular}

Fuente: Portes y Böröcz ${ }^{25}$.

Portes y Böröcz ${ }^{26}$ aseguran que lo común, en la mayoría de los contextos, es que el inmigrado se encuentre con una acogida hostil extendida tanto a los trabajadores manuales

22 PORTES, Alejandro y RUMBAUT, Rubén G., América inmigrante, Anthropos Editorial, Barcelona, 2010.

${ }^{23} \mathrm{ZHOU}$, Min, "Revisiting ethnic entrepreneurship: convergences, controversies and conceptual advancements" en International Migration Review, vol. 38 no 3, 2004, pp: 1040-1074.

${ }^{24}$ Según Bonacich, el término "minoría" implica subordinación y estar en menor número -si bien en algunas ocasiones, y durante ciertos períodos, la minoría podría constituir una mayoría numérica-. Por su parte, el término "intermediario"es más complejo, ya que se coloca en una situación paradójica, pues, de un lado, aparece mezclado junto al éxito económico $y$, de otro, muestra un escaso poder político.Véase BONACICH, Edna, "A theory of middelman minorities" en American Sociological Review, vol. 38, nº 5, 1973, pp: 583-594.

25 PORTES, Alejandro y BOROCZ, József, "Contemporary Inmigration: Theoretical Perspectives on its Determinants and Modes of Incorporation" en International Migration Review, vol. 23, n 3, 1989, pp: 606-630.

${ }^{26}$ Ibídem 
como a los profesionales técnicos y a los empresarios ${ }^{27}$. Esto se manifiesta cuando las estructuras de oportunidad ${ }^{28}$ de la inserción laboral de los inmigrados están definidas por los agentes sociales y económicos del contexto y no tanto por el capital humano de los trabajadores.

\section{6. ¿Qué pasa en la actualidad en Río Cuarto con los horticultores bolivianos?}

En el caso de Río Cuarto, entonces, de acuerdo con la clasificación elaborada por los distintos autores, nos estaríamos refiriendo, por un lado, al primer caso mencionado, es decir a economías de enclave étnico, ya que tanto los patrones bolivianos como los trabajadores bolivianos viven en el área de las quintas donde desarrollan la actividad, y por otro, en el caso de los trabajadores, a una situación de neutral a favorable, en la medida que luego de trabajar algunos años para un patrón boliviano o argentino, los empleados migrantes tienen posibilidad de acceder a ser dueños de una pequeña empresa - quinta hortícola-.

Si pasamos a desarrollar sus particularidades, observaremos que:

Los puestos de trabajo que ocupan los inmigrantes en Río Cuarto son específicos, casi todos se centran en la agricultura y la producción de ladrillos ${ }^{29}$, y en menor porcentaje, en la construcción. Veamos esquemáticamente las características de los mercados hortícolas tomadores de trabajo.

En el sector agrario periurbano, dominado por la producción hortícola en fresco, los inmigrantes bolivianos irrumpen con fuerza a mediados de la década de los noventa del siglo pasado. Su incorporación se produce por varios motivos. Primero, por el aumento de las demandas de productos que componen la comida rápida - básicamente, verduras de hoja y tomate-. Segundo, gracias al progreso técnico y científico, que ha posibilitado una mayor producción en una misma temporada - al haberse incorporado el invernadero, las semillas híbridas y el riego por aspersión-, y, por último, debido al abandono de las tareas hortícolas por parte de algunos miembros del grupo doméstico tradicional; en particular, los hijos de los horticultores tradicionales.

La mano de obra local se ha ido insertando fundamentalmente en el sector servicios. De esta manera, se ha generado un trasvase de mano de obra autóctona de unos puestos a otros en función de los niveles de aceptabilidad, deseabilidad y formación de los individuos.

Una de las características del mercado de trabajo hortícola que genera poca deseabilidad y aceptabilidad entre los autóctonos es su flexibilidad, y las exigencias horarias

${ }^{27}$ En un contexto hostil, los empresarios derivan hacia las minorías intermediarias: "Cuando los grupos dominantes de la sociedad receptora tienen una opinión negativa sobre la llegada de actividades de estos inmigrantes, a menudo se ven reducidos al papel de comerciantes marginales". Ibíd.

${ }^{28}$ WALDINGER, Roger et al. (edits.), Ethnic entrepreneurs, Sage Publications, Londres, 1990.

29 "La comunidad boliviana de Río Cuarto y alrededores está conformada por más de dos mil personas. Muchas de ellas viven en los mismos lugares donde desarrollan su actividad: en la zona de hornos ladrilleros de Tres Acequias, y en los campos de cultivo de Las Higueras. Junto con la construcción, ésos son los principales rubros donde trabajan los inmigrantes bolivianos...", indicó Félix Gutiérrez, presidente de la comunidad boliviana de Río Cuarto, en el acto por el Día de la Independencia de Bolivia. REDACCIÓN, "Para la comunidad boliviana, va en retroceso la discriminación laboral" en Puntal, Río Cuarto, Córdoba, Argentina, 03 de Agosto de 2013. Disponible en http://www.puntal.com.ar/noticia.php?id=153578 [consultado el 13 de Septiembre de 2017] 
-el trabajo en la quinta no tiene horario definido; es una actividad muy ardua y esforzada, tanto en épocas de siembra como de cosecha; en particular, cuando hay que administrar varios cultivos simultáneos por temporada- y de días por semana - por ejemplo, hay que trabajar parte del sábado y del domingo para poder llevar verdura fresca al mercado el día lunes-. La demanda de mano de obra en este mercado es fluctuante, hay momentos donde se necesita mucha - sembrado y cosecha - frente a otros que no precisan tanta -cuidado y regado-. Por tanto, su reclutamiento se encuentra sujeto a diversas coyunturas: variaciones en las demandas y necesidades del mercado o bien la necesidad puntual de los agricultores frente a un incremento del ritmo de la recolección. Esto desemboca, en cierta forma, en una situación conformada por menos trabajadores que los necesarios en cada momento, pero de presencia permanente, que en determinados momentos deben esforzarse en trabajar y en otros pueden realizar su tarea "normalmente", que se soluciona renegando del salario y proponiendo trabajar como mediero o medianero, aportando mano de obra de su propia familia.

Como consecuencia de lo anterior, el mercado de trabajo hortícola se sustenta de mano de obra en negro, con anomalías en la remuneración. La estacionalidad de las necesidades de mano de obra lleva al agricultor a no querer dar de alta y regularizar a sus trabajadores, primero, por tener que pagar lo establecido en convenio y, segundo, porque en cierto modo esto obliga a garantizarle una continuidad en el trabajo. Por tanto, si el inmigrante tiene la posibilidad, en el mejor de los casos, de trabajar como mediero, aportando él la mano de obra que se necesite, en parte puede compensar el esfuerzo, porque estaría ganando a porcentaje con mano de obra de su propia familia.

Otra característica de este mercado laboral son sus malas condiciones de trabajo y el alto riesgo de contraer enfermedades. Con referencia a lo primero, dentro del invernadero en épocas estivales se llegan a alcanzar los 50 grados de temperatura y las tareas son siempre duras, ya que requieren de un constante esfuerzo físico. Además, se trata de una labor sometida al contacto con productos fitosanitarios de manipulación peligrosa, habitualmente sin las medidas de protección necesarias. Esto nos lleva a lo segundo: la aparición de enfermedades dermatológicas e infecciosas. Igualmente, fruto de las labores agrícolas, son muy frecuentes las lesiones musculares y las hernias discales.

Por todo ello, el trabajo en la horticultura está muy denostado entre la población activa nacional. En definitiva, podemos decir que el mercado de trabajo hortícola se caracteriza en Argentina y en Río Cuarto, en particular, por su etnificación, flexibilidad y eventualidad en las contrataciones, así como por la precariedad laboral.

No obstante lo cual, ese trabajador, que a menudo suple con miembros de su propia familia la realización de las actividades de los trabajadores que hipotéticamente se necesitarían, acepta dichas condiciones para poder aprender una tarea que más tarde podrá contribuir a que pueda independizarse $y$, con el tiempo, tener acceso a su propio establecimiento.

\section{No obstante, no todo no es tan idílico, porque...}

En los cuatro últimos años, aparte del afianzamiento de la etnia boliviana en Río Cuarto, acaecieron dos hechos sociales de violencia en relación con el rechazo que sintieron algunos 
pobladores locales respecto del éxito alcanzado por aquéllos.

En primer lugar, al asumir en 2014 una nueva comisión en la dirección del Mercado de Abasto de Río Cuarto, quienes ocuparon los cargos de importancia, horticultores locales que desde hace varios años recelan de los bolivianos por su éxito económico, denunciaron a la AFIP ${ }^{30}$ que éstos no pagaban apropiadamente los impuestos y que tenían trabajadores en negro.

Por estas razones, la AFIP avanzó sobre los horticultores bolivianos, allanando sus establecimientos y cobrando suculentas multas en dinero. No obstante, a pesar de ese avance, los horticultores bolivianos se hicieron cargo y se pusieron al día con los impuestos atrasados; pero no se pudo comprobar la existencia de trabajo en negro.

Por otra parte, hacia fin de ese mismo año se produjo un hecho criminal que fue achacado a bolivianos que vivían en la propia ciudad. Todo comenzó la noche del sábado 3 de setiembre de 2014, ya entrada la madrugada del domingo. Jorge Alexis Rodríguez, de 28 años, trabajador changarín, murió tras ser baleado en el abdomen y en una pierna luego de una pelea en el barrio Las Delicias de Río Cuarto ${ }^{31}$.

Por el hecho fueron detenidas cuatro personas; entre ellas, un joven boliviano sospechoso de ser el responsable de los disparos. Al saberse esto, en el barrio se desató una ola de violencia y xenofobia contra la comunidad boliviana.

Familiares y amigos del fallecido Rodríguez primero atacaron la casilla de la familia del sospechoso, donde la policía decía haber secuestrado un arma. Luego, la agresión se extendió hacia otros habitantes bolivianos del barrio. Posteriormente, 17 familias fueron perseguidas con palos y botellas, golpeadas, les quemaron sus casas y fueron obligados a abandonar el barrio. Todo, ante la atenta mirada de la policía provincial, que no hizo nada en defensa de los agredidos.

Horas después, los mismos vecinos agresores cortaron el puente que une Las Delicias con barrio Alberdi, solicitando la reubicación de esa comunidad boliviana en otro punto de la ciudad. "Que se vayan de Río Cuarto estas personas, se lo vamos a pedir al intendente", dijo la madre de la víctima en una de las marchas realizadas a Tribunales para pedir justicia ${ }^{32}$.

Los ciudadanos bolivianos, por su parte, radicaron una denuncia por xenofobia ante la

${ }^{30}$ La Administración Federal de Ingresos Públicos (AFIP) es un organismo autárquico del Estado argentino dependiente del Ministerio de Hacienda. Es el encargado de la aplicación, percepción, recaudación y fiscalización de las rentas e impuestos nacionales, tanto internos a través de la Dirección General Impositiva, como sobre la nómina salarial a través de la Dirección General de los Recursos de la Seguridad Social, como externos a través de la Dirección General de Aduanas. Asimismo, y dentro de sus atribuciones, le corresponde regular las obligaciones y derechos de los contribuyentes.

${ }^{31}$ El barrio Las Delicias de Río Cuarto es conocido como la Pequeña Bolivia, ya que ahí residen unas 500 familias del país vecino y la mayoría de los 5 mil bolivianos que habitan la ciudad. El lugar está circundado por un río, que da nombre a la localidad, y por el country River Side, donde tiene su residencia el gobernador de la provincia de Córdoba.

32 REDACCIÓN, "Agresiones y xenofobia contra bolivianos en Río Cuarto" en Notas. Periodismo popular, 05 de Septiembre de 2014. Disponible en https://notasperiodismopopular.com.ar/2014/09/05/xenofobia-bolivianosrio-cuarto-cordoba/ [consultado el 12 de Septiembre de 2017] 
Justicia, contando con el apoyo del Observatorio de Derechos Humanos de la Universidad de Río Cuarto, institución que también repudió el ataque.

"Ahora la situación está más tranquila. Hoy vino el cónsul de Bolivia y la presidenta del Instituto Nacional contra la Discriminación, la Xenofobia y el Racismo (INADI) delegación Córdoba y se abrió una instancia de mediación en la Defensoría del Pueblo de Río Cuarto", relató unos días después el coordinador del Observatorio de Derechos Humanos de la Universidad Río Cuarto, en diálogo con la prensa33. "La policía estaba ahí y no hizo nada. La segunda o tercera noche hubo detenidos por los robos y las agresiones. Esto pasó por la falta de respuesta de las autoridades provinciales y el cuestionable accionar de la policía", agregó el coordinador. Y también explicó que, afortunadamente, "...el hermano de la víctima puso paños fríos e hizo un llamado a la concordia. Dijo que la comunidad boliviana no tiene que ver con el crimen. Fue fundamental la aparición de este joven"34.

Por su parte, Félix Gutiérrez, líder de la comunidad boliviana en Río Cuarto, también hizo declaraciones a los medios.

"Pedimos que se esclarezca el hecho del día sábado, que den a conocer a los verdaderos responsables y que les caiga la justicia con todo el rigor. Que no tengamos que pagar justos por pecadores. Nosotros somos bolivianos, no delincuentes, somos gente trabajadora", dijo ${ }^{35}$.

El dirigente comunitario también agradeció al hermano de la víctima, "que ha manifestado su apoyo permanente a la comunidad. Es un sector particular el que está llamando a la violencia, quieren delinquir aprovechando el dolor de una familia. Nosotros nunca vinimos a usurpar un terreno ni a quitar un trabajo"36.

Aparece en estos relatos, por primera vez en forma pública en Río Cuarto, un cuadro de xenofobia hacia una comunidad que, económicamente y en la preferencia de los patrones -quinteros, constructores-, ha superado y desplazado a la población local. Un rencor, que permanecía oculto, brotó de golpe, en ese acto cuasi salvaje, contra una etnia que había logrado alcanzar lo que los moradores locales no habían podido.

Poco tiempo después, dos acciones, provenientes de instituciones oficiales locales, la Universidad Nacional de Río Cuarto (UNRC) y el representante local del gobierno provincial trataron de suturar la herida que produjo el conflicto, a partir de propuestas oficiales que reconocieran la existencia de esta población boliviana en la ciudad.

\subsection{Se jugó en el campus de la Universidad el Torneo de Fútbol Patria Grande ${ }^{37}$.}

\footnotetext{
${ }^{33}$ Ibídem.

${ }^{34}$ REDACCIÓN, "Agresiones y xenofobia contra bolivianos...op.cit.

35 Ibídem

${ }^{36}$ REDACCIÓN, "Violencia xenófoba en Argentina: pacifican el barrio de los bolivianos" en eju!, 05 de Septiembre de 2014. Disponible en: http://eju.tv/2014/09/violencia-xenfoba-en-argentina-pacifican-el-barrio-de-losbolivianos/ [consultado el 12 de Septiembre de 2017]

${ }^{37}$ Material provisto por Secretaría de Bienestar-UNRC, Dirección de Prensa y Difusión-UNRC.
} 
Una gacetilla de la Secretaría de Bienestar de la Universidad Nacional de Río Cuarto se distribuyó online y se hizo llegar a los periódicos locales, en la que se expresaba:

"El sábado 18 y el domingo 19 de julio de 2015 se desarrolló un encuentro en el campo de deportes de la UNRC, bajo el nombre de Torneo de Fútbol PATRIA GRANDE. Esta actividad tuvo el objetivo de generar una instancia de formación e integración entre los miembros de la colectividad boliviana de Río Cuarto, aprovechando la ocasión para difundir cuáles son los derechos y obligaciones que tienen como inmigrantes".

El campeonato contó con la participación de veinte equipos de fútbol masculino que compiten en la liga boliviana de fútbol de Rio Cuarto, y de diez equipos de fútbol femenino de la citada Liga, junto con la colaboración de los beneficiarios del Programa "Lideres Deportivos Comunitarios", dependiente de la Secretaría de Deportes de la Nación.

El acto de apertura se realizó el sábado 18 de julio a las 10 en la cancha de fútbol nueve situada al lado del gimnasio mayor de la UNRC, donde nunca dejó de sonar la música típica de Bolivia. El presidente de la comunidad boliviana en Río Cuarto, Rogelio Apaza, abrió la serie de discursos y luego habló el vicerrector de la UNRC, Jorge González; a continuación, lo hizo la Directora de la Delegación Córdoba del INADI ${ }^{38}$, Adriana Domínguez, y, para finalizar, habló el representante del Ministerio de Justicia y Derechos Humanos, de la Presidencia de la Nación, Facundo Gribaudo, quien detalló los objetivos y modalidades del torneo.

También estuvieron presentes el secretario de Desarrollo Social del Gabinete del Sur, Juan Manuel Llamosas; intendentes de la región, autoridades municipales locales y otras autoridades universitarias.

Rogelio Apaza manifestó que el fútbol forma parte del deporte más vinculante de la colectividad, y que están buscando un terreno, han gestionado la personería jurídica y han mandado cartas a la Provincia, a la Municipalidad, al Concejo Deliberante. Destacó que "no quieren que les regalen un lugar", sino que piensan en "pagarlo con los fondos de la comunidad, necesitamos un espacio para compartir", ${ }^{39}$ relató. También tienen la idea de levantar allí una sede social que pueda servir como punto de encuentro de la colectividad. Planifican ahí la realización de talleres y actividades culturales.

Por su parte el vicerrector de la UNRC, Jorge González, dio la bienvenida al evento y expresó que "...la UNRC debe estar abierta a este tipo de actividades; no creemos que pueda estar aislada de procesos de integración latinoamericana...". A su vez, señaló que "... el deporte une, homogeneiza, nos hace iguales, no existen diferencias de clases. Representa esa posibilidad de generar vínculos..." ${ }^{40}$.

Adelantó, también, que la UNRC gestionaría la alternativa de realizar campeonatos de

\footnotetext{
${ }^{38}$ El Instituto Nacional contra la Discriminación, Xenofobia y el Racismo (INADI) es un organismo nacional del Estado Argentino que tiene como fin combatir la discriminación en todas sus formas.

39 Material provisto por Secretaría de Bienestar-UNRC, Dirección de Prensa y Difusión-UNRC.

${ }^{40}$ Material provisto por Secretaría de Bienestar-UNRC, Dirección de Prensa y Difusión-UNRC.
} 
manera permanente en el predio para seguir manteniendo conexión con la colectividad.

En tanto que Adriana Domínguez, directora de la Delegación Córdoba del INADI, enfatizó que estas jornadas deportivas también sirven para que los ciudadanos conozcan sus derechos y obligaciones en el marco de las charlas sobre las normativas laborales, migratorias y de violencia de género.
También recordó que
"la ley de migraciones - dictada durante el gobierno del presidente Néstor Kirchner - es única en Latinoamérica y una de las mejores de todo el mundo. $Y$ esa normativa les da muchas garantías para que estén en este país en la plenitud de sus derechos. Y ellos deben saber la obligatoriedad para con las leyes de nuestro país. Por ejemplo, con el tema del trabajo infantil y la explotación laboral, que en muchas ocasiones se da entre la misma comunidad"41.

La Universidad participó en la organización desde la Dirección de Educación Física, Deportes y Recreación de la Secretaría de Bienestar, y para ello se realizaron varias reuniones con Facundo Gribaudo donde éste solicito las canchas de futbol - seis-, su marcación, redes y el trabajo del personal no docente del área, aulas del gimnasio mayor y el quincho de la zona de las pileta.

El paisaje que se observó en las canchas de futbol de la UNRC fue distinto del habitual; en el aire se escuchó la música del Altiplano, se sintió el olor típico de la comida de la comunidad boliviana, la familia acompañó; la excusa de esta convocatoria fue un torneo de fútbol, cuando realmente el objetivo de ella era crear un "espacio de convivencia entre la población local y la comunidad que viene de distintas regiones de nuestro hermano país".

Mucho público asistió a los encuentros del futbol femenino, jugadoras que se destacaban por su despliegue y también las madres que apenas salían de jugar, cumplían su rol de mamá, amamantando a sus pequeños hijos. Muchos niños jugando a la pelota, mezclados con los adultos. Apenas quedaba un arco libre, éste era ocupado por pequeños futbolistas, con todas las ilusiones de hacer un gol.

En ese marco, la Secretaría de Derechos Humanos de la Nación también dictó Talleres sobre Trata de Personas y Violencia de Género; además, la Delegación de Córdoba del Ministerio de Trabajo, Empleo y Seguridad Social de la Nación, y la Gerencia local de Empleo y Capacitación Laboral (GECAL), informaron y realizaron difusión sobre derechos laborales.

${ }^{41}$ Ibídem. 


\subsection{El festejo del Día de la Independencia de Bolivia}

Por su parte, el Día de la Independencia de Bolivia, el 6 de agosto del mismo año, el gobierno municipal hizo llegar la siguiente invitación a los vecinos de la ciudad de Río Cuarto:

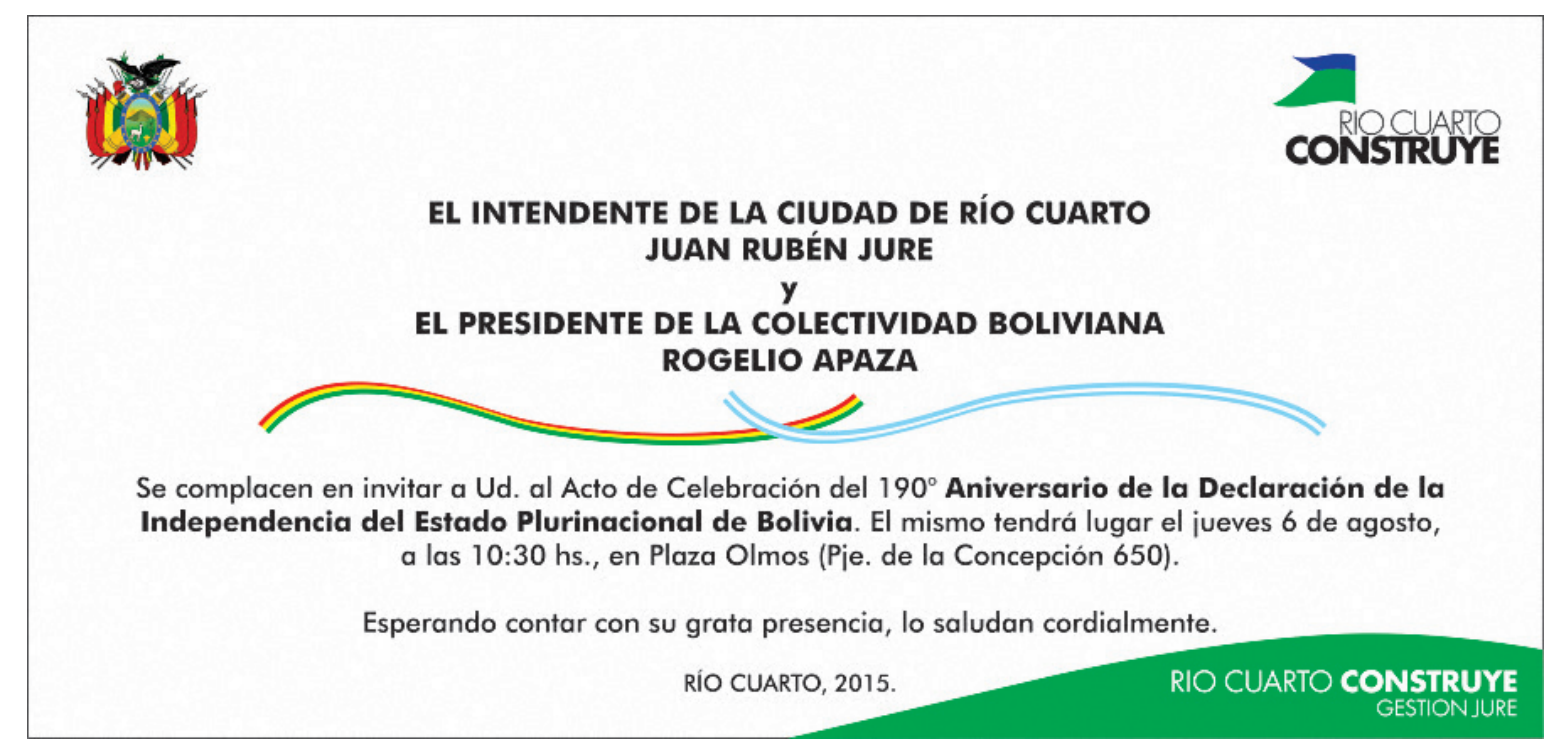

\section{Conclusiones}

A través de este escrito, hemos tratado de mostrar, por un lado, las capacidades de una mano de obra migrante que no necesariamente estaba especializada en la horticultura en su origen, y que en la actualidad ha posibilitado la construcción de espacios de producción y/o comercialización que se reconocen como economías de propiedad étnica y como economías étnicamente controladas, donde hay propietarios bolivianos de establecimientos hortícolas, con empleados bolivianos, en un caso, y propietarios autóctonos de establecimientos hortícolas donde la mayoría o la totalidad de los empleados son bolivianos, en el otro. En ambos tipos de establecimientos se producen alimentos para una clientela en su gran mayoría no étnica.

La importancia de este proceso reside en el hecho de que dichos migrantes, haciendo uso de estas capacidades, han logrado construir "territorios productivos" en áreas donde éstos no existían, así como ser predominantes en mercados tradicionales de distribución mayorista.

Por otra parte, hemos procurado mostrar las reacciones conflictivas que el anclaje de una comunidad étnica en un territorio puede llegar a producir sobre una parte de la población local, y cómo, por otra parte, las instituciones sociales educativas -como la universidady políticas -como la Intendencia Municipal- salen en defensa de una mano de obra que ha venido para quedarse, reconociendo la importancia económica que representa para una ciudad de tamaño intermedio en el interior de la Argentina.

\section{Bibliografía}

AGÜERO, Daniel y GROSSO, Liliana,El sector hortícola del cinturón verde de Río Cuarto, Facultad de Agronomía y Veterinaria, Universidad Nacional de Río Cuarto, 2004.

ARJONA GARRIDO, Angeles. Inmigración y mercado de trabajo. El caso de la economía étnica en Almería, Universidad de Almería, Almería, 2004. 
ARJONA GARRIDO, Angeles y OLMOS, Juan Carlos, "Emprendedores étnicos en Almería. ¿Una alternativa laboral a la segmentación del mercado de trabajo?" en Sociología del Trabajo, Nueva Epoca, no 54, primavera, Madrid, 2005, pp: 101-126.

ARJONA GARRIDO, Angeles y OLMOS, Juan Carlos, "Economía étnica. Teoría, conceptos y nuevos avances" en Revista Internacional de Sociología, vol. LXIV, no 45, septiembre-diciembre, 2006.

BENENCIA, Roberto y GEYMONAT, Marcela, "Migración transnacional y redes sociales en la creación de territorios productivos en la Argentina. Río Cuarto, Córdoba" en Cuadernos de Desarrollo Rural, no 55, 2005, pp. 9-28.

BENENCIA, Roberto, "El mercado de trabajo en las economías étnicas bolivianas en la horticultura de la Argentina. Procesos de constitución y de transformación a inicios de la década" en BENENCIA, Roberto y APARICIO, Susana (Coordinadores) Nuevas formas de contratación en el trabajo agrario, Ediciones CICCUS, Buenos Aires, 2014.

BENENCIA, Roberto, QUARANTA, Germán y ALEGRE, Silvina, "Organización socio-productiva de la horticultura del partido de Florencio Varela" en Boletín Hortícola, INTA Buenos Aires, 2013.

BENENCIA, Roberto, HERRERA LIMA, Fernando y LEVINE, Elaine (Coordinadores), Ser migrante latinoamericano, ser vulnerable, trabajar precariamente, Anthropos Editorial, Universidad Autónoma Metropolitana, México, 2012.

BENENCIA, Roberto, RAMOS, Diego y SALUSSO, Fabricio, "Inserción de horticultores bolivianos en Río Cuarto. Procesos de inmigración, trabajo y conformación de economías étnicas" en Mundo Agrario, vol. 17, no. 36, La Plata, Argentina, 2016.

BONACICH, Edna, "A theory of middelman minorities" en American Sociological Review, vol. 38, no 5, 1973, pp: 583-594.

CORRAL, Mario; GROSSO, Liliana; RITCHER, Carlos; DAURIA, Raúl; CRESPI, Ricardo; FABRICIUS, Alberto; Rivetti, Jorge; CANTERO, Juan José; NUÑEZ, Carlos; GIL, Horacio y VILLALBA, Jorge, Diagnóstico y evolución del área frutihortícola de Río Cuarto,Comisión de Desarrollo Regional, Universidad Nacional de Río Cuarto, Río Cuarto, 1993.

LIGHT, Ivan y KARAGEORGIS, Stavros, "The ethnic economy" en SMELSER, Neil y SWEDEMBERG, Richard (edit.) The handbook of economic sociology, Nueva York, Russell Sage Foundations, 1994, pp:650-677.

LOGAN, John R., ALBA, Richard y McNULTY, T.L., "Ethnic Economies in Metropolitan Regions. Miami and Beyond" en Social Forces, no 72, 1994.

PORTES, Alejandro y WILSON, Kenneth. "Immigrants enclave: An analysis of the labor market experiences of Cubans in Miami" en American Journal Sociology, vol. 86, no 2, 1980, pp: 295-319.

PORTES, Alejandro y JENSEN, Leif, "The enclave and the entrants: patterns of ethnic enterprise in Miami before Mariel" en American Sociological Review, vol. 54, no 6, 1989, pp: 929-949.

PORTES, Alejandro y BOROCZ, József, "Contemporary Inmigration: Theoretical Perspectives on its Determinants and Modes of Incorporation" en International Migration Review, vol. 23, no 3, 1989, pp: 606-630.

PORTES, Alejandro y RUMBAUT, Rubén G., América inmigrante, Anthropos Editorial, Barcelona, 2010.

TORRES, Francisco, La inserción de los inmigrantes. Luces y sombras de un proceso,Talasa Ediciones, Madrid, 2012.

WALDINGER, Roger; ALDRICH, Howard y Ward, Robin (edits.), Ethnic entrepreneurs, Sage Publications, Londres, 1990.

ZHOU, Min, "Revisiting ethnic entrepreneurship: convergences, controversies and conceptual advancements" en International Migration Review, vol. 38 no 3, 2004, pp: 1040-1074.

Artículos periodísticos

REDACCIÓN, "Joven riocuartense muere baleado por un grupo armado" en CBA 24h, 03 de Septiembre de 2014. Disponible en: http://www.cba24n.com.ar/content/joven-riocuartense-muerebaleado-por-un-grupo-armado [consultado el 12 de Septiembre de 2017]

REDACCIÓN, "Agresiones y xenofobia contra bolivianos en Río Cuarto" en Notas. Periodismo popular, 05 de Septiembre de 2014. Disponible en https://notasperiodismopopular.com.ar/2014/09/05/ xenofobia-bolivianos-rio-cuarto-cordoba/ [consultado el 12 de Septiembre de 2017]

REDACCIÓN, "Para la comunidad boliviana, va en retroceso la discriminación laboral" en Puntal, Río Cuarto, Córdoba, Argentina, 03 de Agosto de 2013. Disponible en http://www.puntal.com.ar/ noticia.php?id=153578 [consultado el 13 de Septiembre de 2017]

REDACCIÓN, "Una fiesta de la cultura de Bolivia para celebrar su independencia", en Puntal, Río Cuarto, Córdoba, Argentina, 04 de Agosto de 2014. Disponible en: http://www.puntal.com.ar/noticia. php?id=176678 [consultado el 12 de Septiembre de 2017]

REDACCIÓN, "Violencia xenófoba en Argentina: pacifican el barrio de los bolivianos" en eju!, 05 de Septiembre de 2014. Disponible en: http://eju.tv/2014/09/violencia-xenfoba-en-argentinapacifican-el-barrio-de-los-bolivianos/ [consultado el 12 de Septiembre de 2017] 


\section{RELACIONES INTERNACIONALES}

Revista académica cuatrimestral de publicación electrónica Grupo de Estudios de Relaciones Internacionales (GERI) Universidad Autónoma de Madrid, España

www.relacionesinternacionales.info

ISSN 1699 - 3950

ff facebook.com/RelacionesInternacionales

twitter.com/RRInternacional 